\title{
L'ENSENYAMENT DE LA LLENGUA: REPTES ACTUALS I DE SEMPRE
}

\author{
Professors de l'àrea de Didàctica de la Llengua
}

\section{La cruïlla}

Quins reptes deixa l'ensenyament de la llengua per al proper mil.lenni?

Aquesta és la pregunta que molts dels professionals del camp de la didàctica de la llengua ens podem fer avui. I és que els reptes, tot i que no són pas nous -fa anys que els arrosseguem-, sembla que reapareixen quan la societat en general es dedica a fer balanç. "Avui a l'escoles no s'ensenya llengua com abans. Abans les nenes i els nens no feien faltes d'ortografia, tenien bona lletra... Avui ni en el món universitari es pot trobar estudiants que escriguin bé". Les faltes d'ortografia, la mala lletra, els barbarismes, la pobresa del lèxic, la manca de coherència argumentativa, els nuls hàbits lectors, etc. formen part de la llista de greuges que sembla que la societat té contra l'actual ensenyament de la llengua.

Però ja no s'hi val, a caure en el parany del culpable immediat: que la universitat ho atribueixi a la manera d'ensenyar de l'institut; que aquest en faci culpable l'escola primària; aquesta, el parvulari, etc. Perquè, si és cert que tots els que formem part de la xarxa educativa del país tenim la nostra responsabilitat, també ho és que el problema ultrapassa la mateixa realitat educativa.

Quan diem abans, a quin temps en referim, a quaranta, cinquanta, seixanta anys? Evidentment, a la memòria dels que ara estem fent l'anàlisi dels fets. Per aquest motiu creiem que seria bo reflexionar sobre aquest repte, tenint en compte el punt de comparació:

Abans els estudiants arribaven millor que ara en tot allò que fa referència a la llengua escrita a la universitat. D'acord, però:

a) Quants estudiants arribaven a la universitat? Molt pocs.

b) Quins tipus de estudiants omplien la universitat? El milloret de cada escola, i fills de famílies motivades, molt majoritàriament de classes alta i mitjana.

c) Abans, quina llengua s'ensenyava, com es feia i quins continguts s'impartien? L'ortografia i la cal-ligrafia eren les reines de totes les activitats. Un dictat es demanava per a l'ingrés al batxillerat. El concepte que la lengua és comunicació s'ha introduït al món de la didàctica fa aproximadament 30 anys.

d) Abans com vivia el jovent les normes socials? Eren respectades pel jovent, en general; actualment aquest col-lectiu s'ha alliberat de certs costums rígids, i les actituds transgressores de moltes fórmules de comportament social es fan evidents dia a dia.

Tenim, doncs, una situació molt diferent a la que vam viure molts dels que ara ens lamentem dels pocs avenços que es fa en l'ensenyament de la llengua. Avui per avui una escola ja és per a tothom -on tothom ha se saber llegir i escriure, i evidentment, bé-; s'han obert noves perspectives dins el camp de l'estudi de la llengua -la llengua no solament són normes per escriure correctament, sinó que també és comunicació-; i per últim, els colllectius joves no assumeixen les normes com fa quaranta anys-les normatives ortogràfiques no encaixen-. L'escola, la universitat, intenten assumir els canvis socials que vivim per poder donar resposta a les necessitats educatives. Així, l'escola ha de saber assumir la diversitat dels seus alumnes, com ho ha de fer també la universitat, ja que el món del treball cada vegada s'allunya més dels joves, i li toca emparar gran nombre d'estudiants amb interessos diversos. Aquesta realitat ha generat preocupacions als ensenyants de llengua, els quals han anat obrint camins de treball, de recerca de didàctica... però han crescut proporcionalment les dificultats amb el nombre de publicacions. Com ens ho hem de fer, doncs?

\section{Llegir}

Pel que fa a la lectura, no voldríem caure o quedar-nos simplement en el tòpic que es llegeix poc, ni tampoc farem esment de les estadístiques freqüentment publicades. Es tracta d'un fet col-lectivament incòmode, al qual més o menys recursivament tothom es refereix, i quasi sempre -per la nostra part- recomanant als nostres alumnes la necessitat d'adquirir els recursos que els permetran, com a futurs professionals, inculcar en els seus alumnes -al cap i a la fi, en el sistema educatiu- l'hàbit de la lectura com a únic mitjà d'eradicar la falta d'interès pels llibres que arrossega la nostra cultura, i a la vegada d'introduir-los en el plaer per la lectura.

Però sembla que no acabem de plantejar-nos seriosament els problemes pràctics que provoca aquest índex baix de lectura. En primer lloc, per què és dolent o què té de dolent el fet de llegir poc? I en segon lloc, i suposant que no llegir sigui dolent, com es pot corregir? 


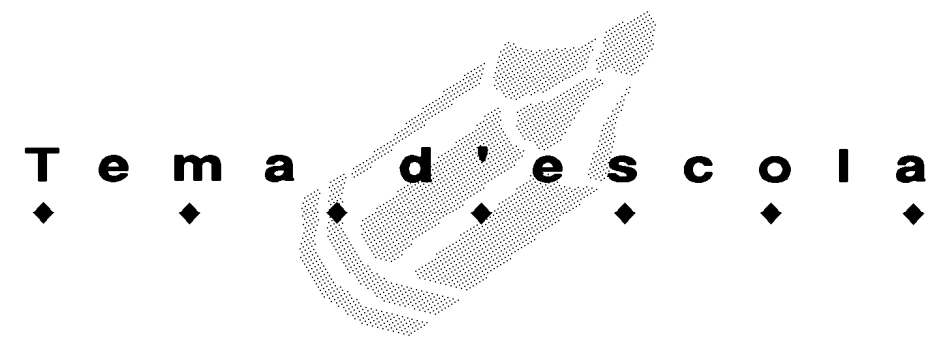

Amb la universalització de l'ensenyament ha anat paral.lela l'adquisició i la difusió de la capacitat tècnica de la lectura i l'escriptura, però no hem de passar de llarg que vivim en un món en què les alternatives a llegir són cada vegada més nombroses i temptadores: l'electrònica i la informàtica posen al nostre abast mitjans de comunicació moderns i eficaços. La lectura sembla una activitat antiquada: els llibres són objectes arcaics. Tots aquests elements juguen seriosament contra I'hàbit de la lectura. Ara bé, des d'un punt de vista pràctic, llegir té dues vessants: la lúdica i la productiva. L'important és que llegint, fins i tot quan ens divertim, aprenem. Lamentablement, per molt que nosaltres prediquem, sembla que el nostre sistema educatiu no acaba d'inculcar suficientment l'hàbit lector, però també perquè es dóna una mena de cercle familiar viciós. Si els pares no llegeixen, els fills tampoc no ho fan. Però la lectura exclusivament productiva té una difícil substitució, avui per avui, pels mitjans audiovisuals, ja que requereix un esforç intel.lectual, un esforç formatiu que ens fa reflexius i racionals, que ens ensenya a escriure, sobretot durant la infantesa i en l'adolescència, i a més és un hàbit a adquirir en aquestes etapes.

Què cal fer, doncs, per estimular l'hàbit de llegir? En teoria, una cosa molt senzilla, peró dificilíssima en la pràctica: millorar el nivell educatiu a les escoles i universitats, tot inculcant l'hàbit d'estudi i adjudicant a la lectura un nou paper que no el faci quedar relegat a una simple eina d'aprenentatge, sinó que esdevingui un element cabdal que ens ha de servir per adquirir coneixements, per sentir plaer i per entendre la realitat que ens envolta.

\section{Escriure}

Els objectius i els continguts dels currículum escolars s'estan replantejant contínuament i s'adapten a la realitat i a les necessitats actuals, tant en superfície com en profunditat. En aquest sentit, el cas de l'escriptura és representatiu.

L'assumpte és complicat. És ja tradicional que els mestres diguem i pensem que els alumnes -siguin de l'edat que siguin- no saben escriure; que no saben redactar i fan faltes. Però el més greu és que en molts casos és cert.

Deixant en segon terme el tema de l'ortografia, o millor dit, integrant-la com un aspecte més en l'expressió escrita, l'aprenentatge de l'escriptura ens presenta actualment diversos reptes. Un d'ells està ja teòricament assumit, tot i que potser només teòricament: es tracta de plantejar l'ensenyament de l'escriptura des de la perspectiva del mitjà de comunicació que és, de fer una escriptura «per a la vida». L'escola que assumeix aquest repte planteja una escriptura «útil»» i funcional, i crea situacions de comunicació perquè l'expressió escrita tingui la motivació social que té a la vida quotidiana. Un altre repte està en l'escolarització obligatòria, que arriba fins als setze anys. Aquest fet comporta que l'escriptura no pot plantejar-se només des de la perspectiva social, sinó també des de l'acadèmica. El nen serà avaluat, en un bon percentatge, per la seva capacitat d'expressar-se, d'exposar les seves idees per escrit, de redactar treballs, etc. I això no sols a la universitat o al batxillerat, sinó a l'ensenyament obligatori. El text expositiu i el text argumentatiu tenen, doncs, a l'àmbit acadèmic un lloc fonamental, i s'hauran «d'ensenyar», s'haurà d'ajudar el nen perquè els aprengui a fer.

No podem admetre el «salvi's qui pugui»; o el que és el mateix, no podem exigir al nen competències i habilitats que no li hem ensenyat i potser ni tan sols endevinat. Aquí l'escola té un paper important. Es tracta d'una formació que haurà de continuar al centre de secundària, però que no s'ha d'oblidar al de primària per dos motius importants. En primer lloc, els textos expositius, com els argumentatius, es fonamenten en el rigor, en la claredat de les idees i en la seva exposició. Ensenyen a separar l'essencial de l'accessori, ensenyen a expressar-se amb la lògica adequada a cada discurs: ensenyen a escriure. I en segon lloc, amb el text expositiu especialment s'expressen el pensaments i els coneixements, però també es millora el coneixement: s'associen idees, s'estructuren conceptes i hom arriba a conclusions. És a dir, escrivint s'expressen els pensaments, però també es pensa, i s'aprèn a pensar.

L'escola no ha ignorat el repte del treball acadèmic: proposa treballs de grup o individuals per a l'elaboració dels quals s'han de consultar llibres, extreure idees, ordenar-les, etc., i d'alguna manera dóna pistes per realitzarlos. En els millors casos es treballa per projectes. Però potser el repte més important que pot fixar-se l'escola en relació a l'escriptura és el del treball ben fet, el de l'actitud crítica de l'estudiant davant de la seva producció escrita.

I l'escola pot fer molt per aconseguir aquest objectiu: ha de proporcionar coneixements sobre la llengua anant més enllà de la gramàtica de la frase, de manera que els nens coneguin implícitament la importància de la coherència, la cohesió, etc. Però, sobretot, l'escola ha de facilitar els mitjans perquè el nen aprengui que l'escriptura és un fet conscient en funció d'un propòsit o d'un projecte d'actuació, i que això comporta una organització de diferents tasques, que van des de la planificació a la textualització, a la revisió i en molts casos a la reescriptura. És a dir, escriure bé necessita temps. I el mestre necessita temps per ensenyar a buscar informació, ajudar a generar idees, estructurar-les, revisar-les, etc. El repte del treball escrit ben fet passa per no saltar-se cap fase del procés de l'escriptura, passa per tenir temps, valor per cert molt car en una escola quartejada pels horaris i esclavitzada pels llibres de text. La interdisciplinarietat i la vida estan, com sempre, en la base de la millora de qualsevol àrea del currículum. 